\title{
Man-Made and Natural Fibres as a Reinforcement in Fully Biodegradable Polymer Composites: A Concise Study
}

\author{
Stanislaw Frackowiak ${ }^{1} \cdot$ Joanna Ludwiczak $^{1} \cdot$ Karol Leluk $^{1}$
}

Published online: 18 September 2018

(c) The Author(s) 2018

\begin{abstract}
Biodegradable and ecologically friendly polymer materials attract great attention of many scientific groups in the world as they fit well in the sustainable development policy and are considered to be "a right thing to do" by the general public. Such polymers can be modified by the addition of different fillers, favorably of natural origin. In the paper we provide a comparison between composites based on two biodegradable polymers: poly(lactic acid)—biodegradable, natural stock polymer and poly(butylene succinate) — biodegradable polymer produced from fossil based materials. For each polymer we have prepared a series of composites with different fibres (natural: hemp and flax, and manmade: Cordenka) and different filler loadings. To fully characterize obtained materials thermal, mechanical and surface free energy measurements were performed, completed with morphology observations and an attempt to compare the experimental data for tensile measurements with values obtained using the modified rule of mixtures. The tensile results calculated using the modified rule of mixture for below $30 \%$ fibre loading are found to be fitting the experimental data. Composites mechanical properties and morphology were strongly affected by the type of fibre used and its loading, however thermal properties remained almost unchanged. In specific, Cordenka fibres tend to form bunches which presence greatly influences the mechanical properties but still our studies have shown clear advantage of manmade Cordenka fibres over the hemp and flax fibres when considering distribution and fibre-polymer interaction.
\end{abstract}

Keywords Biodegradable composite $\cdot$ Cordenka $\cdot$ Poly(lactid acid)

\section{Introduction}

During the last few decades natural fibres have gained a strong focus in the field of polymer composites fillers [1-4]. Their potential derivates from low density, low price, relatively high mechanical strength, biodegradability, and natural feel-like which is important for the end customer as we tend to select products that remind us nature made objects (i.e. wood, wool etc.) [5].

Of course, there are some drawbacks like low moisture resistance, problems with compatibility when compounding with a hydrophobic polymer matrix or inconsistence in chemical composition. Like most of the fibres used in polymer composites manufacturing, natural fibres are also prone

Stanislaw Frackowiak

stanislaw.frackowiak@pwr.edu.pl

1 Department of Environmental Engineering, Wroclaw University of Science and Technology, Wybrzeze Wyspianskiego 27, 50-370 Wroclaw, Poland to forming aggregates and have to be modified accordingly in order to prevent that phenomena. One other drawback that is specific to natural fibres is the influence of their origin on the fibres properties. As they are not manufactured, but rather grown, there are some farming related factors having an impact on crop end properties [6-8]. For now also the cost effectiveness of natural fibres when compared to synthetic equivalents is rather low but recent life cycle analyses have proven natural composites more ecologically favorable as they require $30 \%$ less energy when compared to their synthetic counterparts [9].

In the past few years man made natural fibres have attracted attention as a polymer composite fillers, since they are of similar quality as a conventional natural fibres, but their drawbacks are in most part decreased [10-16]. One of such fibres, with excellent properties recurrence is Cordenka. It is produced by a type of viscose process, where natural cellulose pulp is being dissolved in a sodium hydroxide and carbon disulphide solution. Then after some mechanical treatment (ripping, 
filtration) is extruded into a final fibre form. It has high thermal stability, good adhesion and a very high quality dimension stability [17]. The comparison between two general types of fibres, manmade Cordenka and naturally occurring hemp and flax fibres in biodegradable polymer such as PLA was needed. There are many examples in the literature of composites based on polymers from non-renewable resources, PE or PP for example. Natural fibres with their hydrophilicity and thusly poor adhesion to hydrophobic polymers should have a better interaction with the hydrophilic PLA. On the other hand, more stable and repeatable properties of Cordenka fibres could prove to be of better quality as a composite filler.

Basing on the different hydrophilic character of those two type of fillers there was a curiosity to compare resulting hydrophilic character of polymer composites filled in three different filling ratio. Interactions in polymer matrix-fibred material systems are mainly of chemical nature but they can modify physical side (surface morphology) of polymer systems as well. It is well known fact, that surface of composites filled with high ratio of modifier differ substantially from those filled with minor level. Performing wettability measurements on different surfaces of composites gives an insight into chemical nature of modified polymer system as well their morphology and allow to conclude in a quantitative way.

Also, surface free energy measurements were performed to add the overall knowledge to the paper as polymer surfaces are often difficult to wet and bond, which is caused by incompatibility, presence of contaminants, factors connected with weak boundary layers etc. The knowledge of polymer composite surface properties plays a crucial role in preparing processes like coating, joining, printing and other. Determining surface energy properties for polymerfibre compositions is very important as such materials have broad area of applications (engineering, automotive industry, construction) in many cases coated, printed on or joined with other materials.

In this paper we evaluate and compare properties of different fully biodegradable polymer composites based on two different matrixes, poly(lactic acid) biodegradable, natural stock polymer and poly(butylene succinate), biodegradable polymer produced from fossil based materials.

\section{Experimental}

\section{Materials and Composites Preparation}

Composites were prepared by melt mixing of polymer matrices, polylactic acid PLA 3052D from NatureWorks and poly(butylene succinate) PBE 003 BB from NaturePlast with fibres. Hemp and flax were $4 \mathrm{~mm}$ long, kindly supplied by EKOTEX Poland. Their processing was narrowed down only to number of processes necessary for their extraction from the plant. No additional treatment (in particular surface activation) was applied to filler material.

Viscose fibres were supplied by Cordenka $\mathrm{GmbH}$ under the commercial name Cordenka ${ }^{\circledR}$.

\section{Samples Preparation}

Composites were prepared by melt mixing of polymer matrix (PLA and PBS) with hemp, flax and Cordenka fibres. Mixing was performed using a Thermo Scientific Polylab QC equipped with internal mixer (roller rotors) with a chamber temperature of $180^{\circ} \mathrm{C}$ and rotor speed of $50 \mathrm{rpm}$. Filler concentration was 10;30; $50 \mathrm{wt} \%$. Mixing time varied from 5 to $6 \mathrm{~min}$, as derived from the on-line torque measurements. Each composite was processed until the torque reached a stable value, which depended on the filler type and concentration.

Samples for mechanical testing were prepared using injection molding machine (Proma) at $180^{\circ} \mathrm{C}$. Samples dimensions were $120 \times 10 \times 4 \mathrm{~mm}$, respectively.

\section{Mechanical Testing}

All mechanical tests were performed at relative humidity of 50\% and room temperature. The specimens had been conditioned under the same circumstances for at least $24 \mathrm{~h}$ before testing. The tensile strength and the Young's modulus were determined according to ISO 527 standard using Lloyd LR10K test machine operated at a crosshead speed of $10 \mathrm{~mm} / \mathrm{min}$. Samples used were dogbone-shaped with gauge length of $35 \mathrm{~mm}$. The Charpy impact strength of the composites was tested according to ISO 179 standard using Resil 5.5 CEAST testing machine with a pendulum of $4 \mathrm{~J}$ energy. The specimens were rectangular in shape, unnotched.

\section{Dynamic Scanning Calorimetry}

Dynamic scanning calorimetry measurements were performed on the 5-10 mg samples in heat-cool-heat mode using DSC Q20 (TA Instruments) apparatus. All experiments were conducted at the heating rate of $10{ }^{\circ} \mathrm{C} / \mathrm{min}$, in the temperature range 20 up to $180{ }^{\circ} \mathrm{C}$. Temperatures characteristic for thermal transitions of the material were read out from the second heating scan. Samples were not additionally processed prior to DSC measurement. 


\section{Scanning Electron Microscopy}

Scanning electron microscopy examination was performed to characterize surface morphology. Fractured samples (in liquid nitrogen) were gold sputtered prior to experiment. SEM observations and sputtering were performed using VEGA TESCAN microscope and Kressington 108 sputtering device (respectively). All images were collected at the same magnification rate $-\times 400$.

\section{Surface Free Energy}

Wettability of the samples was measured by means of three liquids system: distilled water, formamide and diiodomethane. All chemicals were at least $99.5 \%$ pure and supplied from Sigma Aldrich. At least five points were taken into consideration when calculating contact angle mean value and its standard deviation. Surface free energy was calculated in terms of van Oss-ChaudhuryGood model [18-20].

\section{Results and Discussion}

\section{Tensile Strength}

In order to evaluate mechanical properties of obtained materials, tensile tests were performed. Since the middle of twentieth century, many theoretical models were developed with the aim of modeling the mechanical properties of fibre reinforced composites (FRC). The most common and simplest ones are the rule of mixtures based equations. However, due to incompatibility between the fibres and the polymer matrix, rule of mixtures tends to fail in modeling the composites mechanical properties. By definition, the rule of mixtures describes a rather idealized situation, where it is assumed that uniform strain condition exist in both matrix and the fibre. For most FRC that is not the case. After considering other parameters, such as fibre orientation and fibre length a proper model that will reflect the experimental data can be applied.

Modification of rule of mixture equation was first considered by Cox who showed that for aligned fibres composite modulus is given by:

$Y_{c}=\left(\eta_{1} \eta_{0} Y_{f}-Y_{m}\right) V_{f}+Y_{m}$

where $\mathrm{Y}_{\mathrm{c},}, \mathrm{Y}_{\mathrm{m}}, \mathrm{Y}_{\mathrm{f}}$ are modulus of the composite, matrix and the fibre respectively, $V_{f}$ is the fibre volume, $\eta_{0}$ is the orientation efficiency factor and $\eta_{1}$ is the length efficiency factor.

The length efficiency factor tends to approach 1 at high (above 10) 1/D ratio. In our paper only long fibres were used, with 1/D ratio considerably above that value. As for the fibre alignment, no orientation techniques

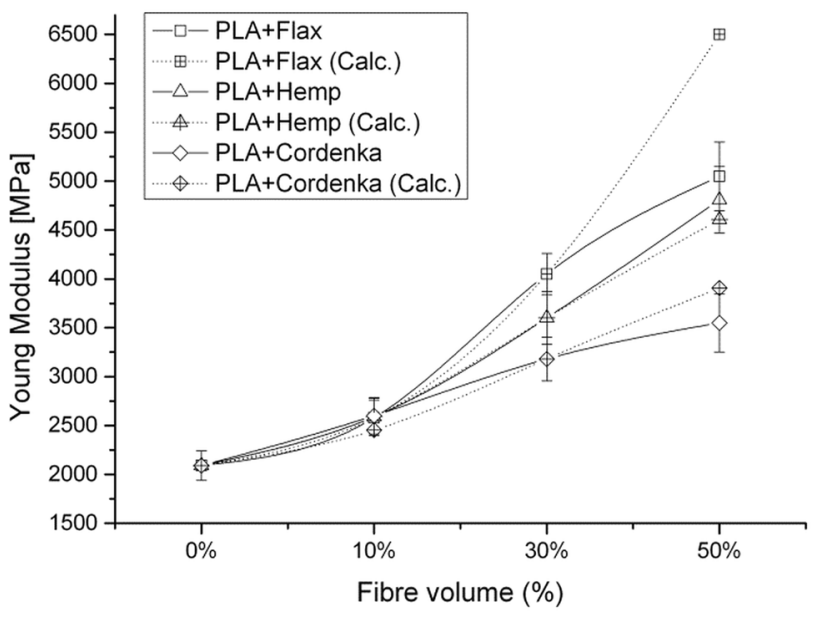

Fig. 1 Young modulus of PLA based composites

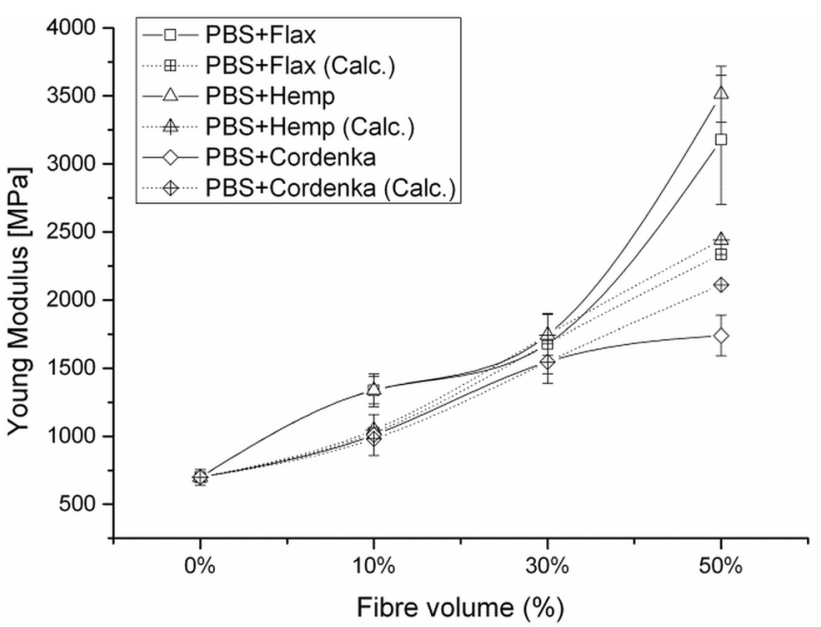

Fig. 2 Young modulus of PBS based composites

were introduced during composite preparation process, therefore based on literature data $\eta_{0}$ was fixed at value of 0.2 as for randomly oriented fibres [21]. Fibres modulus used in calculations (flax $3.49 \times 10^{4} \mathrm{MPa}$, hemp $3.56 \times 10^{4} \mathrm{MPa}$, Cordenka $2.86 \times 10^{4} \mathrm{MPa}$ ) was estimated based on literature data [22].

Comparison of Young modulus calculated versus experimental values for PLA and PBS based composites is presented on Figs. 1 and 2. In terms of composites' stiffness the highest values were achieved by addition of flax fibres, $3100 \mathrm{MPa}$ and $5050 \mathrm{MPa}$ for PLA and PBS based composite respectively. Lower modulus values were obtained for hemp and Cordenka filled composites. The results obtained from a modified rule of mixture calculation fit experimental results well at lower fibre 


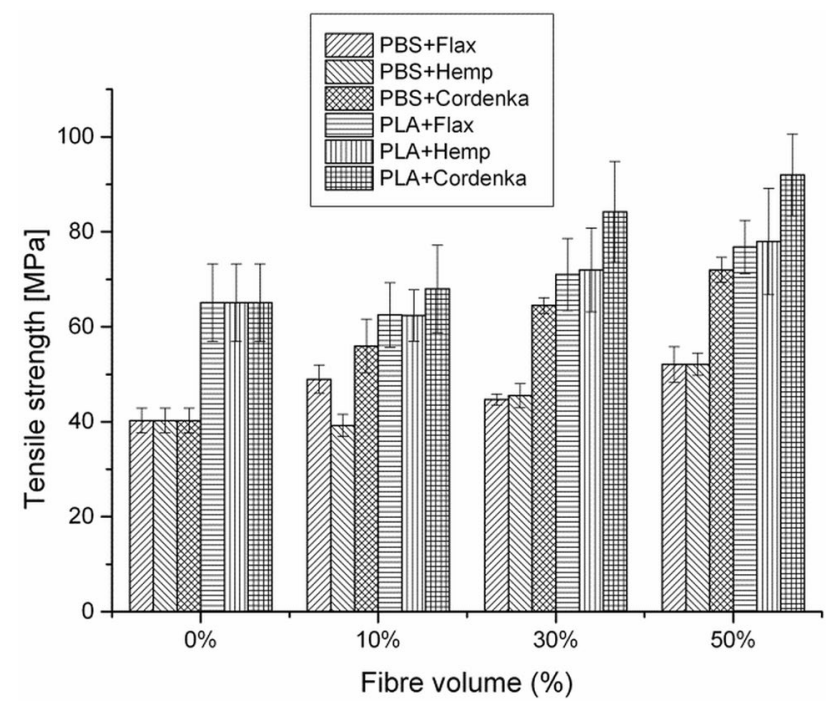

Fig. 3 Tensile strength of PLA and PBS based composites

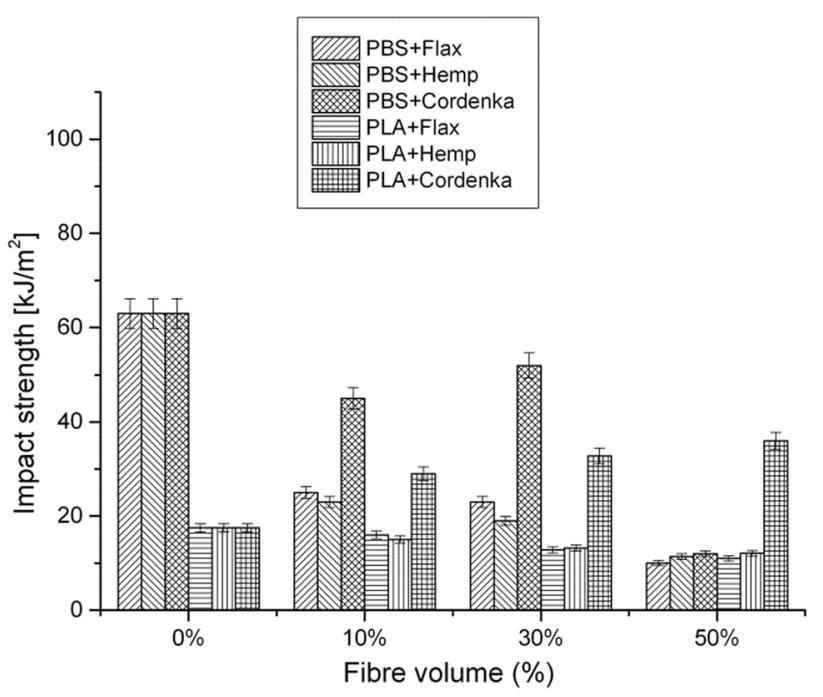

Fig. 4 Impact strength of PLA and PBS based composites filled with different natural fibres

loadings but tend to overestimate modulus values at $50 \%$ loading. Such tendency is known and it is mostly due to not taking into account the defects of the fibre-polymer adhesion area which plays an important role in the transmission of stress from matrix to the fibre and thus contributes toward the performance of the composite.

Tensile strength $\left(\sigma_{\mathrm{c}}\right)$ values for obtained composites are presented on Fig. 3. Pristine polymers were also added for comparison purpose. As expected, one can observe general improvement in tensile strength for all of the implemented fibre types. Neat PLA $\sigma_{\mathrm{c}}$ value of $65 \mathrm{MPa}$ increased up to $76 \mathrm{MPa}$ with flax fibre, $78 \mathrm{MPa}$ with hemp fibre and $88 \mathrm{MPa}$ with Cordenka. For PBS based composites $\left(\sigma_{\mathrm{c}}\right.$ of $\left.40 \mathrm{MPa}\right)$ the tensile strength achieved values of $52 \mathrm{MPa}, 51 \mathrm{MPa}$ and $72 \mathrm{MPa}$ at $50 \%$ loading of flax, hemp and Cordenka fibre respectively. Therefore it can be said that Cordenka filled composites gained most efficiently on tensile strength properties in comparison with hemp and flax.

\section{Impact Properties}

Impact strength of evaluated polymer/fibre systems decreases with the increasing fibre volume, except for PLA/ Cordenka (Fig. 4). PBS based composites impact strength was decreased from 63 to $10 ; 12 ; 13 \mathrm{~kJ} / \mathrm{m}^{2}$ for flax, hemp and Cordenka fibre respectively.

As for PLA/flax composite the impact strength was decreased from 17.5 to $11 \mathrm{~kJ} / \mathrm{m}^{2}$ and PLA/hemp to $12.1 \mathrm{~kJ} /$ $\mathrm{m}^{2}$. The impact strength of Cordenka filled PLA increases significantly and reaches $36.7 \mathrm{~kJ} / \mathrm{m}^{2}$ which doubles the impact strength of pristine PLA.

The results suggest that PBS which has higher impact strength when compared to PLA, is being weakened by the addition of fibres. Although it has to be underlined that for flax and hemp fibre the decrease in PBS impact strength is steady, for Cordenka one can observe a critical fibre volume value of $30 \%$ at which impact strength is $52 \mathrm{~kJ} / \mathrm{m}^{2}$.

For low impact resistant polymer, such as PLA, addition of Cordenka led to obtaining of a reinforced composite. Thus, the impact strength of the PLA/Cordenka composite is more promising than all other biodegradable composites. Such behavior can be explained when considering the fact that the impact strength in fibre reinforced composites is dependent mainly on three factors-fibre fracture, debonding and pull-out. In case of PLA/Cordenka it is assumed that the strain energy which is released by fibre debonding and fracture is proportional to the debonded length. In other words, during impact, part of the energy is absorbed by fibres being pulled out of the polymer matrix due to poor adhesion.

Similar observations were reported by Fink and Hoffman [23] who measured mechanical properties of PLA composites including PLA-Cordenka reinforced polymer systems. Although the main part of their research were provided to reveal the influence of coupling agent on 
Table 1 DSC results

\begin{tabular}{lrllll}
\hline Sample & $T_{g}\left({ }^{\circ} \mathrm{C}\right)$ & $T_{c}\left({ }^{\circ} \mathrm{C}\right)$ & $T_{c c}\left({ }^{\circ} \mathrm{C}\right)$ & $T_{m l}\left({ }^{\circ} \mathrm{C}\right)$ & $T_{m 2}\left({ }^{\circ} \mathrm{C}\right)$ \\
\hline PBS & -29.0 & 76.4 & 100.4 & 114.9 & - \\
PBS + 10\% Cordenka & -29.1 & 83.4 & - & 105.1 & 119.5 \\
PBS + 30\% Cordenka & -28.9 & 83.8 & - & 105.5 & 118.8 \\
PBS + 50\% Cordenka & -28.8 & 83.9 & - & 105.7 & 118.9 \\
PBS + 10\% flax & -30.2 & 85.2 & - & 103.4 & 115.1 \\
PBS +30\% flax & -30.1 & 87.5 & - & 105.4 & 116.6 \\
PBS + 50\% flax & -30.1 & 87.9 & - & 105.9 & 117.0 \\
PBS + 10\% hemp & -30.7 & 83.9 & - & 102.2 & 115.1 \\
PBS + 30\% hemp & -31.5 & 84.6 & - & 102.9 & 115.1 \\
PBS + 50\% hemp & -30.9 & 85.1 & - & 103.4 & 115.2 \\
PLA & 62.3 & - & 114.9 & - & 155.2 \\
PLA+10\% Cordenka & 61.0 & - & 116.3 & 149.0 & 155.1 \\
PLA + 30\% Cordenka & 62.1 & - & 112.3 & 150.9 & 158.0 \\
PLA + 50\% Cordenka & 62.8 & - & 114.1 & 151.2 & 159.1 \\
PLA + 10\% flax & 61.8 & - & 115.8 & 149.8 & 155.8 \\
PLA + 30\% flax & 61.8 & - & 115.2 & 150.6 & 156.7 \\
PLA+50\% flax & 61.9 & - & 115.7 & 151.1 & 157.7 \\
PLA + 10\% hemp & 61.7 & - & 114.7 & 149.8 & 155.3 \\
PLA + 30\% hemp & 61.9 & - & 114.9 & 150.6 & 157.0 \\
PLA + 50\% hemp & 62.1 & - & 114.9 & 151.3 & 158.1 \\
\hline
\end{tabular}

increasing tensile strength, authors described interactions in unmodified polymer-Cordenka systems.

\section{Dynamic Scanning Calorimetry}

DSC results are presented in Table 1. No significant changes may be observed in the PLA samples. Most of the parameters, $T_{g}=62{ }^{\circ} \mathrm{C}$ (glass transition temperature), $T_{c c}=115{ }^{\circ} \mathrm{C}$ (cold crystallization temperature), do not change at all or slightly differ in an unordered manner and the observed differences are equal or less than experimental error. Some dependencies may be attributed to melting $\left(T_{m}\right)$ and crystallization $\left(T_{c}\right)$ temperatures which both increase their value with the filler loading ratio. The change is rather a general observation. For all PLA composites double signals related to melting were observed. According to the literature such a behaviour indicates the coexistence of different crystalline phases of the same material [24, 25]. Low-temperature signal may be attributed to forms formed during cold crystallization process while primarily crystallized species undergo melting indicated by the signal at higher temperature.

A bigger differences were observed for PBS and PBS filled with fibres. PBS is characterized by a $T_{g}$ of $-29{ }^{\circ} \mathrm{C}, T_{c}=76^{\circ} \mathrm{C}, T_{c c}=100{ }^{\circ} \mathrm{C}$ and $T_{m}=115^{\circ} \mathrm{C}$. All composites PBS/fibres have a similar $T_{g}$, while the higher
$T_{c}\left(84-88{ }^{\circ} \mathrm{C}\right)$ as compared to the polymer matrix was observed. DSC curves show two melting peaks for composites, the first at a lower temperature $\left(102-106^{\circ} \mathrm{C}\right)$ and a second at a higher temperature $\left(115-119^{\circ} \mathrm{C}\right)$ (Table 1$)$.

\section{Surface Morphology Characterization}

Presented on the Fig. 5 SEM images of fibrous composites, bring an additional prove of the discussed dependencies observed in mechanical properties examination when analysing the residual fractured surface. Cordenka filled sample present a similar behaviour to two other composites. It is clearly seen that Cordenka fibres are extensively pulled out from the polymer matrix. Therefore part of the impact energy during impact is being absorbed by fibres being pulled out of the polymer matrix (Fig. 6).

Another hint coming out from the micrographs is rather qualitative description than quantitative conclusion. As it comes out from figures depicting fractured Cordenka composites, the number of fibres outreaching from the material's bulk is much greater comparing to natural fibres composites. Being aware of the fact that the volume of all fibres (disregarding the type) added to the polymer matrix during the preparation process remains the same (in the same typeseries), observed phenomenon might be attributed to the matrix behaviour. To clarify the thought: the surface of moulded PLA composite samples appealed a way more smooth character comparing to PBS matrix. Thus fibres behaved as being fluffed (we called it: "Cordenka bunch") although their volume fraction remained unchanged. That observation was also reflected in wetting experiment.

When analysing the polarity character of the PBS based composites, one can notice that in flax and hemp filled samples the polarity increases with the filler ratio (Fig. 7). Both Figs. 7 and 8 represent polar (group of first three bars) and apolar (second triplet) contribution to total SFE.

The explanation relates to the probability of fibres physical presence on the material's surface. The more fibres are embedded within the polymer matrix, more of them are also present on the composite's outer surface increasing in turn composite's polar character (as the fibres are polar). Contrary to that, in Cordenka filled samples the polar character as well as total SFE decreases with the filler ratio. Such a behaviour cannot be simply explained only by physical presence of polar fibres on the composite's surface. SFE is an average parameter describing chemical nature of the investigated material which is reflected by contact angle value. The latter one is an outcome of chemical (e.g.: the polarity) and physical (e.g.: surface porosity) factors. Presence of Cordenka 

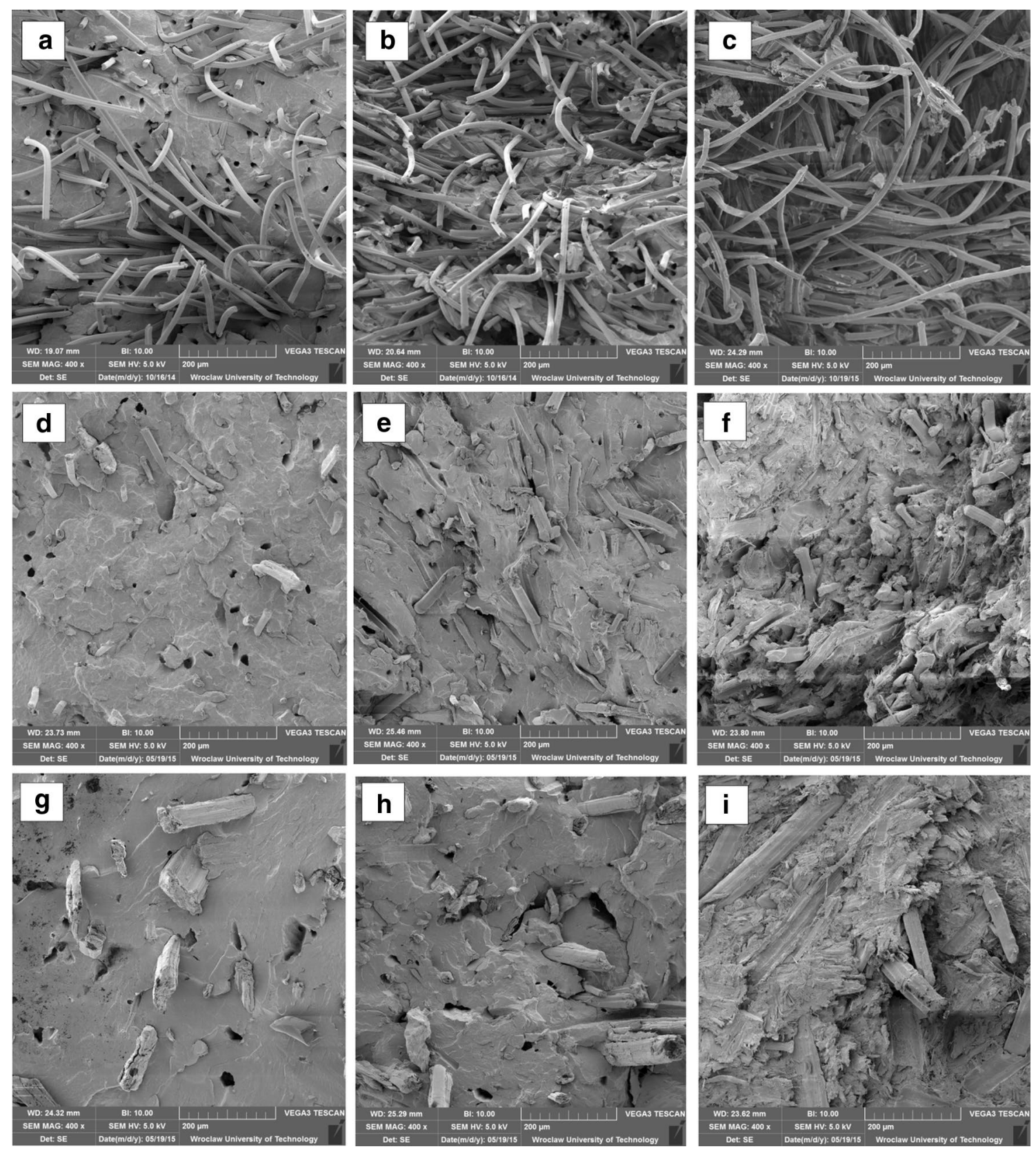

Fig. 5 SEM images of PBS based composites filled with increasing load of Cordenka fibres $(\mathbf{a}-10 \%, \mathbf{b}-30 \%, \mathbf{c}-50 \%)$, flax fibres $(\mathbf{d}, \mathbf{e}, \mathbf{f})$ and hemp fibres $(\mathbf{g}, \mathbf{h}, \mathbf{i})$

bunch affects vastly physically composites surface. That in turn influences the contact angle of measuring liquids making it an apparent one. As an effect, although Cordenka fibres reveal polar character it is their 3D arrangement affecting vastly measured contact angle. This fact is broadly recognized in the literature [26, 27]. In turn measured, apparent, contact angle may indicate that investigated surface reveals more non-polar character than other samples.

The behaviour of PLA based composites is a way different from the discussed PBS samples. The polar character is decreasing with increasing fibre ratio (Fig. 8). 


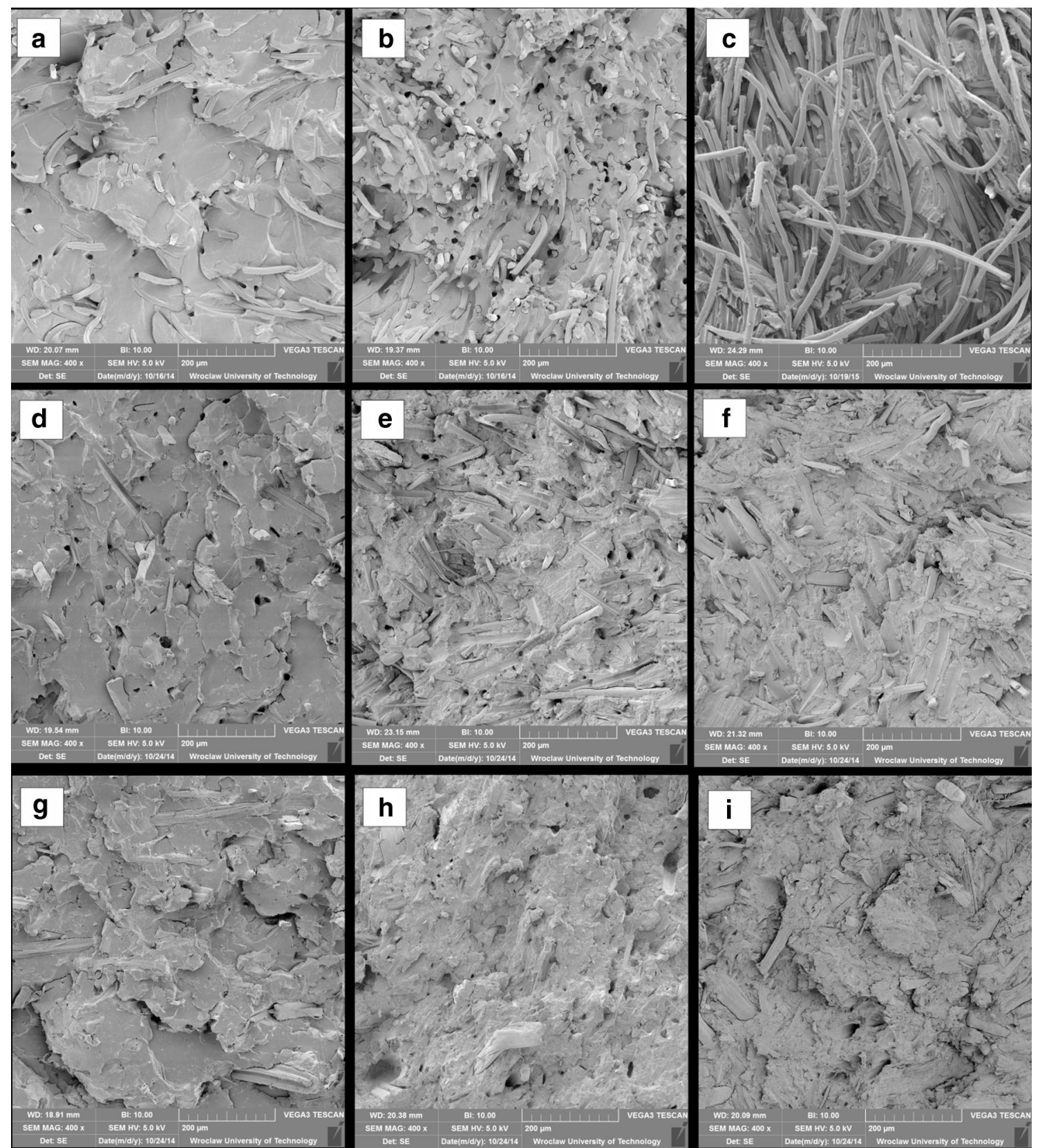

Fig. 6 SEM images of PLA based composites filled with increasing load of Cordenka fibres $(\mathbf{a}-10 \%, \mathbf{b}-30 \%$, $\mathbf{c}-50 \%)$, flax fibres (d, e, f) and hemp fibres $(\mathbf{g}, \mathbf{h}, \mathbf{i})$

\section{Conclusions}

Composite materials based on two biodegradable polymer matrices, PLA and PBS, containing different type and amount of natural fibres were produced. Obtained materials were characterized for tensile, impact and thermal properties.

Tensile results were calculated using the modified rule of mixture and the experimental results fit well at lower (below $30 \%$ ) fibre loadings.
Composites mechanical properties and morphology are strongly affected by the type of fibre used and its loading when the thermal properties remain almost unaffected.

Morphology characterization with SEM confirms well fibre distribution and the advantage of manmade Cordenka fibres over the hemp and flax fibres when considering distribution and fibre-polymer interaction. 


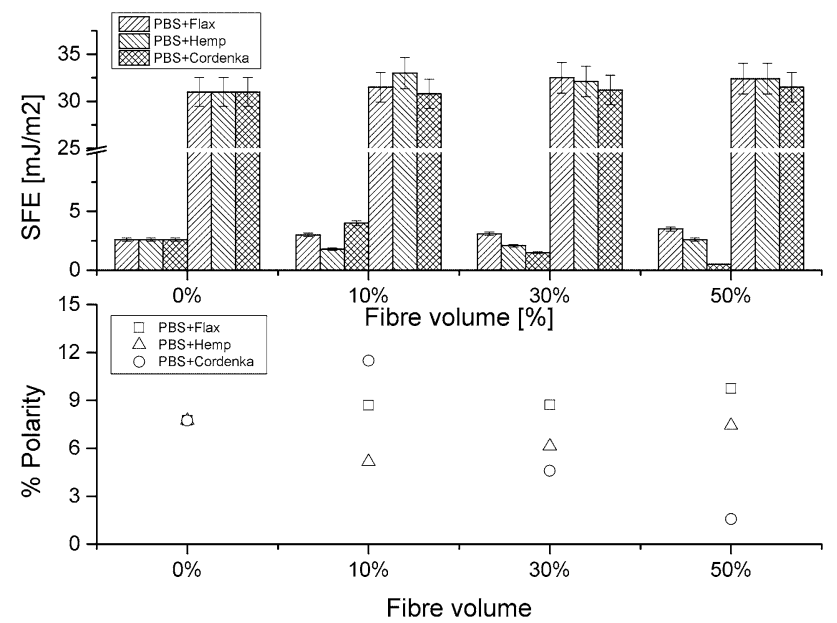

Fig. 7 Surface energy of PBS based composites with natural fibres

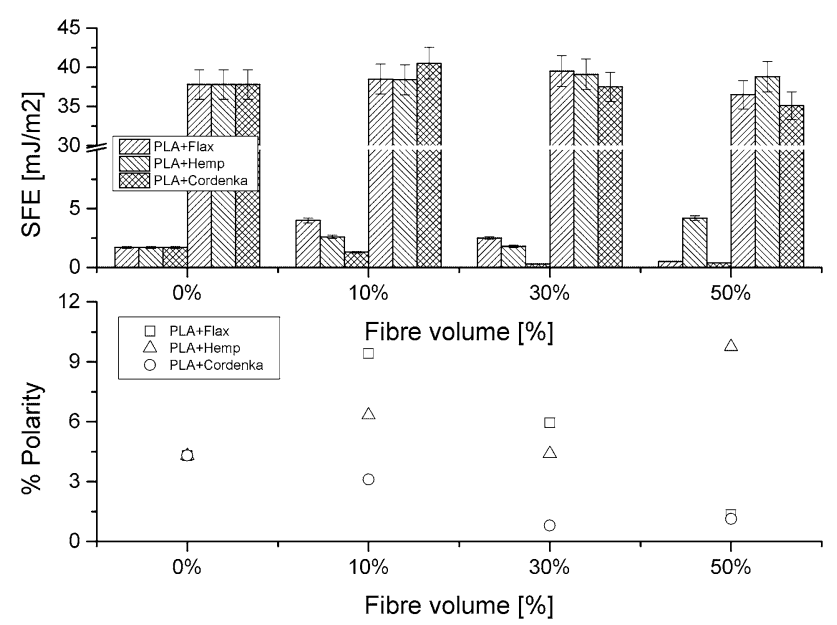

Fig. 8 Surface energy of PLA based composites with natural fibres

Acknowledgements The work was financially supported by Wrocław University of Science and Technology internal financing mechanism $(0401 / 0068 / 16)$.

Open Access This article is distributed under the terms of the Creative Commons Attribution 4.0 International License (http://creativeco mmons.org/licenses/by/4.0/), which permits unrestricted use, distribution, and reproduction in any medium, provided you give appropriate credit to the original author(s) and the source, provide a link to the Creative Commons license, and indicate if changes were made.

\section{References}

1. Moriana R, Vilaplana F, Karlsson S, Ribes A (2014) Correlation of chemical, structural and thermal properties of natural fibres for their sustainable exploitation. Carbohydr Polym. https://doi. org/10.1016/j.carbpol.2014.06.009

2. Sanjay MR, Arpitha GR, Yogesha B (2015) Study on mechanical properties of natural-glass fibre reinforced polymer hybrid composites: a review. Mater Today Proc 2(4-5):2959-2967
3. Bénézet J-C, Stanojlovic-Davidovic A, Bergeret A, Ferry L, Crespy A (2012) Mechanical and physical properties of expanded starch, reinforced by natural fibres. Ind Crops Prod 37(1):435-440

4. Ganster J, Fink H-P (2006) Novel cellulose fibre reinforced thermoplastic materials. Cellulose 13(3):271-280

5. Koronis G, Silva A, Fontul M (2013) Green composites: a review of adequate materials for automotive applications. Composites B 44(1):120-127

6. Jonoobi M, Oladi R, Davoudpour Y, Oksman K, Dufresne A, Hamzeh Y (2015) Different preparation methods and properties of nanostructured cellulose from various natural resources and residues: a review. Cellulose 22(2):935-969

7. Komuraiah A, Kumar NS, Prasad BD (2014) Chemical composition of natural fibres and its influence on their mechanical properties. Mech Compos Mater 50(3):359-376

8. Notta-Cuvier D, Lauro F, Bennani B, Nciri M (2016) Impact of natural variability of flax fibres properties on mechanical behaviour of short-flax-fibre-reinforced polypropylene. J Mater Sci 51(6):2911-2925

9. Dittenber DB, GangaRao HVS (2012) Critical review of recent publications on use of natural composites in infrastructure. Composites A 43(8):1419-1429

10. Majeed K, Jawaid M, Hassan A, Abu Bakar A, Abdul Khalil HPS, Salema AA (2013) Potential materials for food packaging from nanoclay/natural fibres filled hybrid composites. Mater Des 46:391-410

11. Kuranska M, Prociak A (2012) Porous polyurethane composites with natural fibres. Compos Sci Technol 72(2):299-304

12. Arrakhiz FZ, El Achaby M, Malha M, Bensalah MO, Fassi-Fehri O, Bouhfid R (2013) Mechanical and thermal properties of natural fibres reinforced polymer composites: doum/low density polyethylene. Mater Des 43:200-205

13. Meredith J, Ebsworth R, Coles SR, Wood BM, Kirwan K (2012) Natural fibre composite energy absorption structures. Compos Sci Technol 72(2):211-217

14. Hughes M (2011) Defects in natural fibres: their origin, characteristics and implications for natural fibre-reinforced composites. J Mater Sci 47(2):599-609

15. AL-Oqla FM, Sapuan SM (2014) Natural fibre reinforced polymer composites in industrial applications: feasibility of date palm fibres for sustainable automotive industry. J Clean Prod 66:347-354

16. El-Sabbagh A (2014) Effect of coupling agent on natural fibre in natural fibre/polypropylene composites on mechanical and thermal behaviour. Composites B 57:126-135

17. Meredith J, Coles SR, Powe R, Collings E, Cozien-Cazuc S, Weager B (2013) On the static and dynamic properties of flax and Cordenka epoxy composites. Compos Sci Technol 80:31-38

18. Good RJ, Hawaa AK (1997) Acid/base components in the molecular theory of adhesion. J Adhes 63:5-13

19. Van Oss CJ, Chaudhury MK, Good RJ (1988) Interfacial Lifshitzvan der Waals and polar interactions in macroscopic systems. Chem Rev 88:927-941

20. Xiaobo L, Yaobang Z, Wenting L, Guoping C, Wenjin C (2006) Kinetics of thermo-oxidative and thermal degradation of poly(D, L-lactide) (PDLLA) at processing temperature. Polym Degrad Stab 91:3259-3265

21. Matthews F, Rawlings R (1999) Composite materials engineering and science. Woodhead Publishing, Cambridge

22. Wambua P, Ivens J, Verpoest I (2003) Natural fibres: can they replace glass in fibre reinforced plastics? Compos Sci Technol 63(9):1259-1264

23. Fink HP, Hofmann D (2012) Tailor-made polymer research-20 years. Fraunhofer IAP, Potsdam

24. Masirek R, Kulinski Z, Chionna D, Piorkowska E, Pracella M (2007) Composites of poly(L-lactide) with hemp fibres: 
morphology and thermal and mechanical properties. J Appl Polym Sci 105(1):255-268

25. Su Z, Li Q, Liu Y, Hu G-H, Wu C (2009) Multiple melting behavior of poly(lactic acid) filled with modified carbon black. J Polym Sci B 47(20):1971-1980

26. Shiuichi S, Onda T, Satoh N, Tsujii K (1996) Super waterrepellent surfaces resulting from fractal structure. J Phys Chem 100:19512-19517
27. Feng L, Zhang Y, Xi J, Zhu Y, Wang N, Xia F, Jiang L (2008) Petal effect: a superhydrophobic state with high adhesive force. Langmuir 24(8):4114-4119 